\title{
Merkez Kamu Kurumlarındaki Su ve Elektrik Tüketiminde Kurum Yöneticilerinin Rolü: Bursa İli Örneği
}

\author{
Melike YALILI KILIÇ*, Seval Kutlu AKAL SOLMAZ, Ayşe ELMACI \\ Bursa Uludağ Üniversitesi, Mühendislik Fakültesi, Çevre Mühendisliği Bölümü, Bursa \\ (ORCID: 0000-0001-7050-6742) (ORCID: 0000-0002-9413-8005) (ORCID: 0000-0002-1762-1140)
}

\begin{abstract}
$\ddot{O} z$
Güney Marmara Bölgesi’ndeki Bursa ili, yoğun göç alan ve sanayi yönüyle sürekli gelişmekte olan bir il özelliğine sahiptir. Toplam il nüfusu Türkiye İstatistik Kurumu son açılanan verilerine göre 2.901 .396 olan ve 17 ilçesi ile birlikte Türkiye'nin 4.büyük şehridir. Bu çalışmada, Bursa ilinin kamu kurumlarında su ve elektrik enerji kaynaklarının kullanımı ve yönetimine karşı gösterdiği davranışları belirlemeye yönelik Bursa ili merkez ilçelerindeki 30 kamu kurumunda görev yapan 94 kurum yöneticilerine bir anket çalışması uygulanmıştır. Mevcut kaynak kullanımı hakkında ilgili kurum tarafından yapılan çalışmaların kapsamlı şekilde araştırılmasının amaçlandığı bu çalışmada, uygulanan anketlerden elde edilen veriler SPSS programı kullanılarak değerlendirilmiştir. Değerlendirme sonucunda, özellikle öne çıkan hususlar; kamu kurumlarının yöneticilerinin su ve elektrik tasarrufu konusunda duyarlı oldukları, tasarruf konusunda çalışanlarına yönelik düzenli olarak bilgilendirme amaçlı etkinlikler düzenledikleri, kurum binalarının içinde ve dışında ihtiyaç duyulan periyodik bakım, onarım, yenileme çalışmalarını yürüttükleri, kullanılan cihazlarda yüksek enerji sınıfinda olanların tercih edildiği, olarak belirlenmiştir. Bursa halkını ve kamu kurumların bilinçlendirme amacıyla yapılan bu çalışmanın "Doğru su ve elektrik kullanımı" konusunda farkındalık oluşturarak, mevcut kaynakların sürdürülebilirliğinin sağlanabileceği ve gelecekte benzer konularda yapılacak çalışmalara temel teşkil edeceği düşünülmektedir.
\end{abstract}

Anahtar kelimeler: Bursa Kamu Kurumları, Su ve Elektrik İhtiyac1, Su ve Elektrik Tasarrufu, Sürdürülebilir Su Yönetimi.

\section{The Role of Institute Managers in Water and Electrical Consumption in Central Public Institutions: Case Study of Bursa}

\begin{abstract}
Bursa, located in the Southern Marmara Region is constantly developing across the industry and receiving intensive migration. With the total provincial population of 2,901,396 according to Turkey Statistical Institute data, Bursa is Turkey's $4^{\text {th }}$ largest city with 17 district. In this study, a survey study was conducted on 94 institution managers working in 30 public institutions in the central districts of Bursa in order to determine the behavior of Bursa province against the use and management of water and electricity energy resources in public institutions. The data obtained from the survey used in this study, which is aimed to be investigated extensively by the relevant institution, is evaluated by using SPSS program. As a result of the evaluation, it was determined that the managers of public institutions were sensitive about saving water and electricity, organized regular information activities for their employees about the savings, carried out periodic maintenance, repair and renovation works in and outside the institutions, and preferred the high energy class devices. It is thought that this study, which was conducted to raise awareness of Bursa people and public institutions, will raise awareness on the right water and electricity use and that the sustainability of the available resources will be ensured and will be the basis for future studies.
\end{abstract}

Keywords: Bursa Public Institutions, Water and Electricity Requirements, Water and Electricity Saving, Sustainable Water Management.

*Sorumlu yazar: myalili@uludag.edu.tr

Geliş Tarihi: 11.04.2019, Kabul Tarihi: 21.10.2019 


\section{Giriş}

Canlıların yaşamı ve hayatın sürdürülebilirliği için çok önemli bir madde olan su, en küçük canlı organizmadan en büyük canlı varlığa kadar, biyolojik yaşamı ve insan faaliyetlerini ayakta tutmaktadır [1,2]. Dünyadaki su kaynaklarının miktarı kısıtlı olup, aynı zamanda dengeli dağılmadığ 1 görülmektedir. Öyle ki, kullanılabilir ve içilebilir nitelikteki su miktarı ancak \%0,3 mertebesindedir. Dünya nüfusunun yarısına yakını günümüzde su sıkıntısı çekmektedir [3]. Dünya Kaynakları Enstitüsü'nün araştırmalarına göre, yaklaşık 20 yıl sonra Türkiye'nin de içinde bulunduğu birçok ülkenin su kıtlığ1 problemi ile karşı karşıya kalacağı belirtilmektedir [4].

Tüm canlılar suya olduğu kadar enerjiye de ihtiyaç duymaktadırlar. Gelir seviyelerinin artması, yaşam kalitesinin yükselmesi ile enerji ihtiyacı da artmaktadır. Bu ihtiyaç, çeşitli enerji kaynaklarından faydalanılarak karşılanmaktadır. Elektriğin bulunup kullanılır duruma getirilmesinden sonra ise, elektrik enerjisi rahatlkkla ve sıklıkla kullanılan bir enerji olmuştur. Kişi başına yıllık elektrik enerji tüketimi o ülkenin uygarlık derecesinin bir ölçüsü olarak değerlendirilmektedir. Elektrik enerjisi başlıca termik, hidro, nükleer ve diğer kaynaklardan üretilir [5]. Elektrik üretiminin 2017 yılı itibariyle \%'lik dağılımı sırası ile 37 doğal gaz, 33 kömür, 20 hidrolik enerji, 6 rüzgâr, 2 jeotermal enerji ve 2 diğer kaynaklar şeklindedir. Türkiye elektrik enerjisi tüketimi 2017 yılında bir önceki yıla göre \%5,6 artarak 294,9 milyar kWh, elektrik üretimi ise, bir önceki y1la göre \%7,7 oranında artarak 295,5 milyar kWh olarak gerçekleşmiştir [6].

Güney Marmara Bölgesi'nde yer alan ve Osmanlı Devleti'nin ilk başkentliğini yapmış olan Bursa, tarihi, turizmi ve sanayisi ile Türkiye'nin 4. büyük kentidir [7] (Şekil 1).
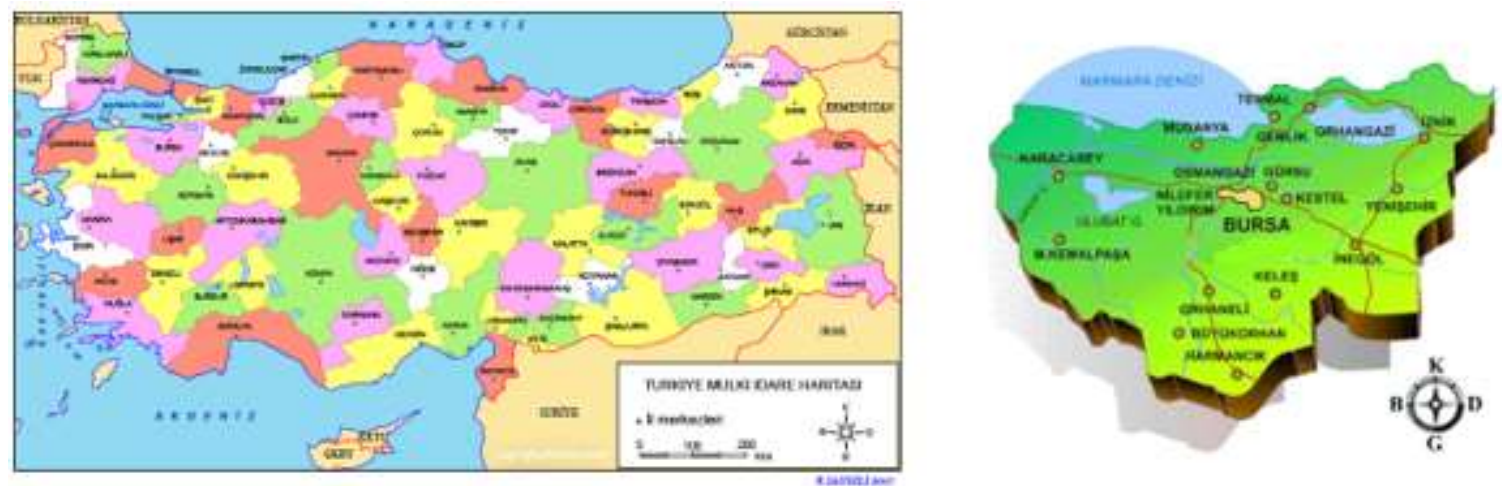

Şekil 1. Bursa'nın Türkiye'deki yer buldurumu [6]

Evliya Çelebi, "Seyahatname" isimli eserinde Bursa'ya övgüler yağdırmış ve su kaynakları açısından Bursa'nın zengin ve şanslı bir il olduğunu belirtmiştir. Bursa ilinin ihtiyaç duyduğu su miktarı günümüzde, Doğancı Barajı, Nilüfer Barajı, Çınarcık Barajı başta olmak üzere pek çok barajdan ve yeraltı su yataklarından karşılanmaktadır [8-14].Gelişen sanayisi ve aldığ 1 göç sebebiyle Bursa'da elektrik enerjisi ihtiyacı gün geçtikçe artmaktadır. Artan bu ihtiyaç günümüzde doğalgaz, kömür, hidrolik, rüzgâr, biyogaz, güneş gibi kaynaklardan temin edilmektedir. Mevcut su ve elektrik miktarı ilde kapasiteyi karşılar düzeyde görünse de, gelecekte sıkıntı yaşanmaması için suyun ve elektriğin temin edildiği kaynakların tasarruflu kullanılmasına yönelik çalışmaların sürdürülmesini zorunlu kılar.

Bu çalışmada Bursa il merkez kamu kurumlarında görev yapan kamu idarecilerinin su-elektrik tüketim alışkanlıkları, su sorunu konusundaki bilgi düzeyi, su kaynaklarının korunması hakkındaki duyarlılığ1, su-elektrik tasarruf önlemleri ve önerilerini belirlemeye yönelik, karşllıklı yüz yüze görüşmelerle bir anket çalışması gerçekleştirilmiştir. Araştırmada Bursa ilinin ele alınmasının temel nedenleri, Bursa'nın yurt içinden ve yurt dışından gelenlerle birlikte göç hareketliliğinin ve dolayısıyla nüfus artış hızının yüksek olması ve bunun sonucunda mevcut su kaynaklarının ve enerjinin artan talepleri karşılamada yetersiz kalabilme ihtimalidir. Diğer bir neden ise, çalışmada ele alınan konu kapsamında bugüne kadar Bursa'da bilimsel anlamda herhangi bir araştırma çalışmasına rastlanmamış olmasıdır. Veri seti hem kalitatif, hem de kantitatif tekniklerden yararlanılarak elde edilen araştırma sonuçlarının, Bursa'da su-elektrik tüketim bilincini arttırmak amacıyla ilgili kişi ve kurumlar tarafından gerçekleştirilecek faaliyetlerde yol gösterici olacağı düşünülmektedir. 


\section{Materyal ve Metot}

Bursa ilinde mevcut merkez kamu kurumlarına yönelik gerçekleştirilen anket çalışması 30 kamu kurumunda görev yapan il müdürleri, şube müdürleri, bölge müdürleri, daire başkanları, genel müdürler ve yönetici yardımcıları olmak üzere toplam 94 kamu yöneticisine uygulanmıştır. Anketin yöneticilere uygulanmasındaki temel neden, su ve elektrik tüketimi açısından daha bilinçli ve daha duyarlı bir şekilde anket sorularına yanıt verileceği ve daha gerçekçi bir değerlendirmenin ortaya konabileceğidir.

Anketin uygulandığı kurumların tamamı Bursa Büyükşehir Belediyesi sınırları içerisinde yer alan kamu kurumları olup, kurumların listesi Tablo 1'de verilmiştir:

Tablo 1. Anketin uygulandığı kamu kurumları ve yönetici sayıları

\begin{tabular}{|c|c|}
\hline Kamu Kurumu & Yönetici Sayısı \\
\hline Bursa Çevre ve Şehircilik İl Müdürlüğü & 3 \\
\hline Bursa Devlet Malzeme Ofisi & 3 \\
\hline Bursa Vergi Dairesi Başkanlığı & 1 \\
\hline Bursa İl Halk Kütüphanesi & 1 \\
\hline Bursa Aile ve Sosyal Politikalar İl Müdürlüğü & 2 \\
\hline Bursa İl Milli Eğitim Müdürlüğü & 5 \\
\hline Bursa Su ve Kanalizasyon İdaresi (BUSKİ) & 8 \\
\hline Bursa İl Sağl1k Müdürlüğü & 3 \\
\hline Bursa Karayolları 14.Bölge Müdürlüğü & 4 \\
\hline Bursa İl Afet ve Acil Durum Müdürlüğü & 3 \\
\hline Bursa İl Kültür ve Turizm Müdürlüğü & 1 \\
\hline Bursa İl Tarım ve Orman Müdürlüğ̈̈ & 4 \\
\hline Bursa Devlet Tiyatrosu & 4 \\
\hline Bursa Tapu ve Kadastro Bölge Müdürlüğü & 2 \\
\hline Bursa İl Nüfus ve Vatandaşl1k Müdürlüğü & 1 \\
\hline Bursa Gençlik Hizmetleri ve Spor İl Müdürlüğü & 1 \\
\hline Bursa Vakıflar Bölge Müdürlüğü & 2 \\
\hline Bursa Büyükşehir Belediyesi & 5 \\
\hline Bursa İl Müftülüğü & 3 \\
\hline Bursa Devlet Su İşleri 1. Bölge Müdürlüğü & 7 \\
\hline Bursa Orman Bölge Müdürlüğü & 6 \\
\hline Bursa Defterdarlığ & 4 \\
\hline Bursa Adliyesi & 3 \\
\hline Sosyal Güvenlik Kurumu Bursa İl Müdürlüğü & 6 \\
\hline Türkiye İş Kurumu Bursa İl Müdürlüğü & 2 \\
\hline Bursa Posta ve Telgraf Teşkilatı İl Müdürlüğü & 1 \\
\hline Bursa Türk Standartları Enstitüsü & 1 \\
\hline Bursa Ticaret İl Müdürlüğü & 1 \\
\hline Bursa Uludağ Gümrük ve Ticaret Bölge Müdürlüğü & 3 \\
\hline Türkiye Elektrik İletim A.Ș. 2. Bölge Müdürlüğü & 4 \\
\hline
\end{tabular}

Toplam 15 sorudan oluşan anket çalışmasında; kurum yöneticilerinin su ve elektrik tüketim alışkanlıkları, su sorunu konusundaki bilgi düzeyleri, su kaynaklarının korunması hakkındaki duyarlılıkları, kurumlarında uyguladıkları su-elektrik tasarruf önlemleri ve önerileri belirlenmeye çalışılmıştır. Anket soruları Tablo 2'de yer almaktadır. 
Tablo 2. Anket çalışmasında yöneltilen sorular

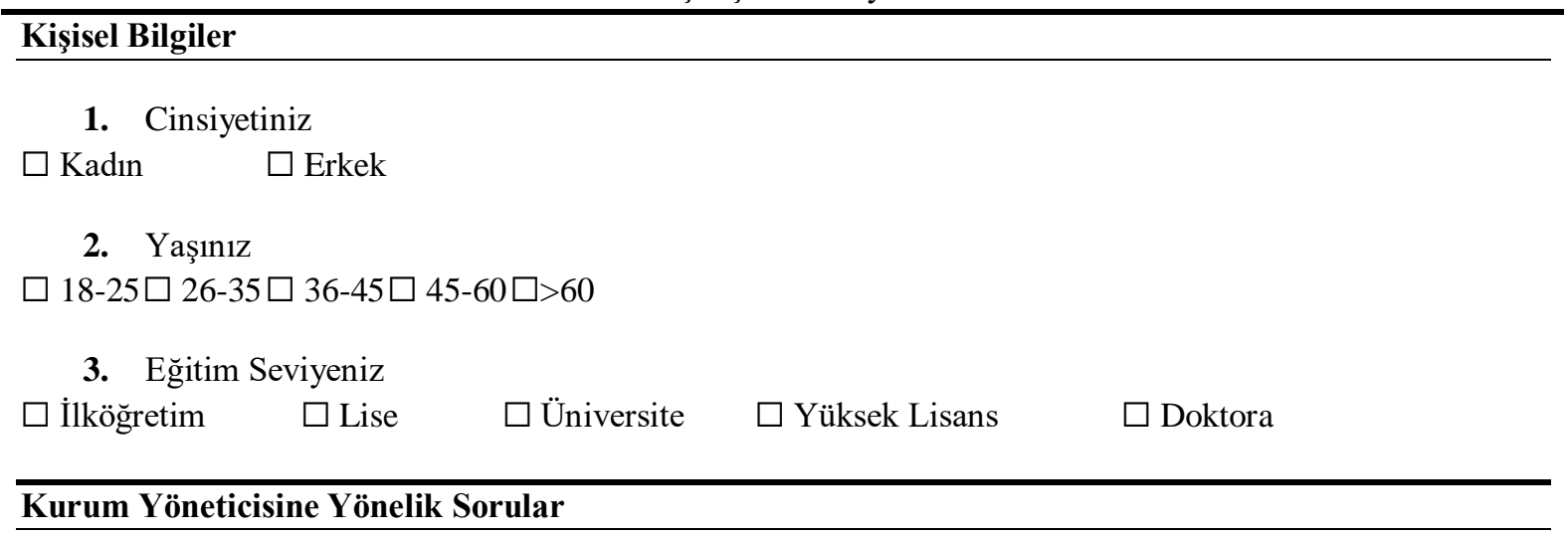

1. Kurumunuzda su veya elektrik tasarrufu ile ilgili bilgilendirme yazısı paylaşıldı mı?

$\square$ Evet $\quad \square$ Hayır $\square$ Bilmiyorum

2. Personele elektrik ve su tasarrufu hakkında seminer düzenleniyor mu?

$\square$ Evet (Açıklayınız..........................................) $\square$ Hayır

3. Kurumda elektrik ve su tasarrufu yönünden denetimler yapılıyor mu?

$\square$ Evet $\quad \square$ Hayır

4. Kurumunuzda 1sınmayı nasıl sağlıyorsunuz?

$\square$ Elektrikli isıtıcı $\quad \square$ Merkezi sistem doğal gaz $\quad \square$ Kombi $\quad \square$ Diğer

5. Binada diş cephe izolasyonu var mı?

$\square$ Evet $\quad \square$ Hayır $\square$ Bilmiyorum

6. Kurum binasında kullanılan camlar çift cam mıdır?

$\square$ Evet $\quad \square$ Hayır (Açıklayınız.........................) $\square$ Bilmiyorum

7. İş yerinizde kullanılan cihazlar tasarruf özelliğine sahip midir?

$\square$ Evet $\quad \square$ Hayır $\square$ Bilmiyorum

8. Bina dışı aydınlatmada herhangi bir tasarruf önlemi kullanılıyor mu?

$\square$ Evet $\quad \square$ Hayır $\square$ Bilmiyorum

9. Büyük ekranlı bilgisayarlar daha çok enerji tükettiği için, kurumunuzda bu konuda belirli bir standart uygulaniyor mu?

Evet $\quad \square$ Hayır $\square$ Bilmiyorum

10. Su dağıtım ve iletim tesisatında TSE damgası olmayan malzeme kullanılıyor mu?

$\square$ Evet $\quad \square$ Hayır $\square$ Bilmiyorum

Uygulanan anket verileri, istatistiksel verileri analiz etmek amacı ile birçok disiplin tarafindan kullanılan SPSS (Statistical Package forthe Social Sciences) [15] bilgisayar yazılımı kullanılarak, frekans tabloları ve bar grafikleri çerçevesinde her kurum ve her soru için istatistiksel olarak değerlendirilmiştir.

\section{Bulgular ve Tartışma}

Çalışma kapsamında, Bursa'da belirlenen 30 kamu kurumunda yönetici pozisyonunda görev yapan 94 yöneticiye uygulanan anket sonucunda elde edilen bulgular aşağıda verilmiştir. Anket çalışmasında kişisel bilgilere yönelik sorular değerlendirildiğinde, yapılan örneklemin 16'sı kadın (\%18), 78'i (\%82) erkek olup, örneklemde kurumlardaki yöneticilerin yaklaşık \%25'inin kadın 
yöneticilerden oluştuğu görülmüştür. Ankete katılanların \%67'i 45-60, \%30’u 36-45, \%2'i 60 yaş üstü ve kalan \%1 ise 26-35 yaş grubunda olduğu tespit edilmiştir. Örneklemede kurumlarda görev yapan yöneticilerden \%98'inin üniversite mezunu olduğu belirlenmiştir. Kurumlardaki yöneticilere görev yaptıkları kurumdaki su ve elektrik tasarrufuna yönelik yöneltilen sorular değerlendirildiğinde aşağıdaki bulgular elde edilmiştir.

Kurumlarda yapılan anket çalışmasında "Kurumunuzda su veya elektrik tasarrufu ile ilgili bilgilendirme yazısı paylaşıldı mı?" sorusuna 94 yöneticinin tamamı evet yanıtını vermiştir.

Ankette "Personele elektrik ve su tasarrufu hakkinda seminer düzenleniyor mu?" sorusuna ankete katılan yöneticilerin tamamı kurumlarında ilgili seminerlerin düzenlendiğini belirtmişlerdir. Seminerler, farklı kamu/özel kurum ve kuruluşlarından destek alınarak düzenlenmiştir.

Kurumlarda yapılan anket çalışmasında "Kurumlarda elektrik ve su tasarrufu yönünden denetimler yapılıyor mи?" sorusuna tüm yöneticilerden "evet" yanıtı alınmıştır. Bu bağlamda, kurumlarda, tasarrufa yönelik uyarı yazılarının personele duyurulduğu, periyodik olarak tasarrufun önemini belirten bilgilendirmelerin yapıldığı ve özellikle yeni inşa edilecek kamu kurum binalarında su ve elektrik tasarrufuna yönelik çalışmaların (klasik armatürlerin fotoselli armatürlerle değiştirilmesi, ofislerde lamba sayılarını azaltılması ve tasarruflu lamba kullanılması, bireysel elektrikli isiticı veya klima kullanımı yerine $1 s 1$ kontrollü merkezi ısıtma ve havalandırma sistemlerinin tercih edilmesi, vb.) planlanmakta olduğu vurgulanmıştır. Su konusunda alınacak her kararın, atılacak her adımın hayati ve son derece önemli olduğunu vurgulayan Fridin 2015 yılında yaptığı çalışmasında [16], insan ve doğanın ayrışması gibi bir durumdan söz edilemeyeceğini, insanın etik ve ahlaki değerlere sahip olduğu takdirde, diğer canlılara da değer vereceğini, onların yaşam hakkına saygı gösterecek şekilde hareket edeceğini ve bu sayede, yaşanılabilir bir çevreye sahip olunabileceğini belirtmiştir.

Anket çalışmasında, 94 yöneticinin tamamı "Kurumunuzda ısınmayı nasıl sağllyorsunuz?" sorusuna, merkezi sistem doğal gaz yanıtını vermiştir. Bu durum, Bursa ili için kamu kurumlarında yakıt ve elektrik tasarrufu açısından doğru bir tercihin göstergesidir.

"Binada dış cephe izolasyonu var mı?" sorusuna ankete iştirak eden yöneticilerin hemen hemen yarısı "evet", 9'u "hayır", geri kalanı ise "bilmiyorum" yanıtını vermiştir (Şekil 2). Kurumlardaki yöneticilerden alınan "evet" yanıtının çoğunlukta olması 1S1 yalıtımına duyarlılık gösterildiğini kanitlamaktadır.

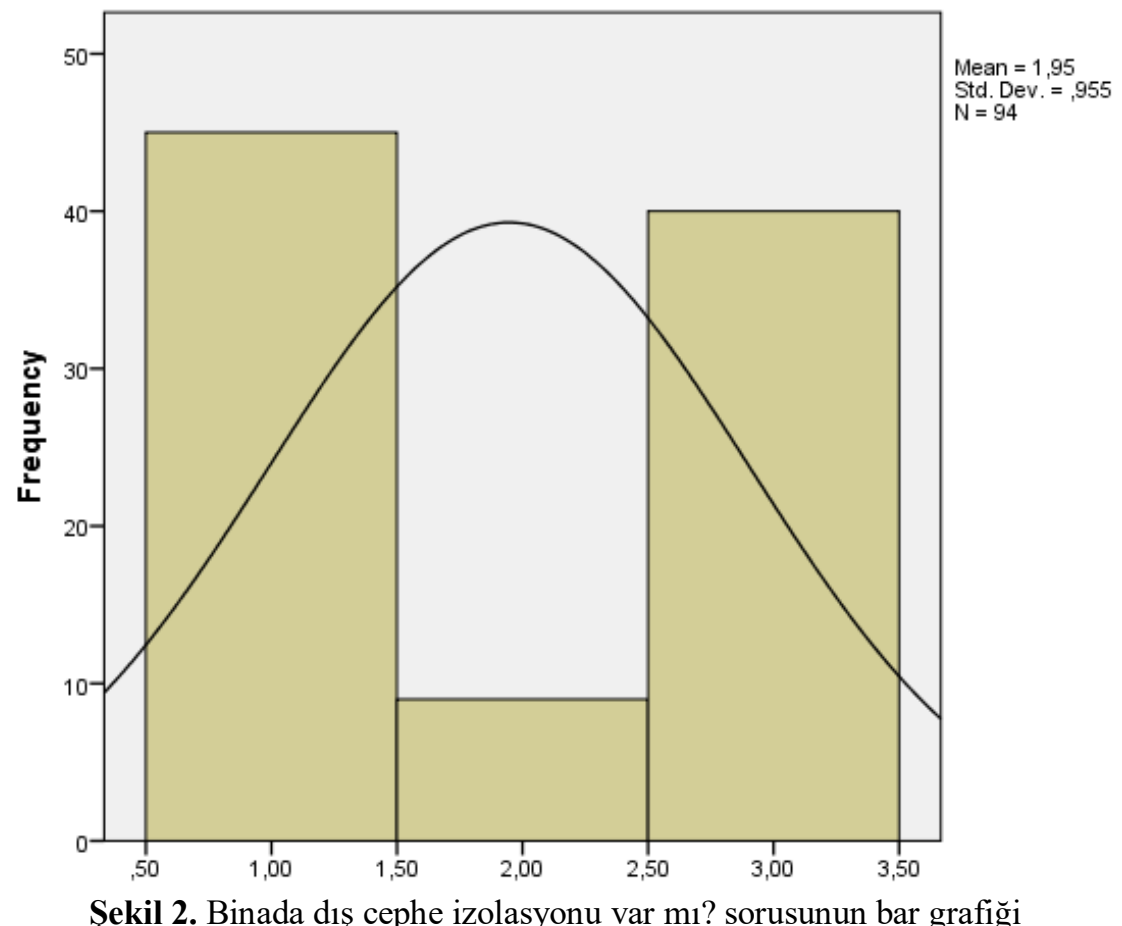

“Kurum binasında kullanılan camlar çift cam mıdır?” sorusuna yöneticilerin tamamına yakını (\%95) "evet" yanıtını vermiştir. Bu durum, enerji tasarrufu açısından çevreci bir yaklaşımı göstermektedir. 
Yöneticiler, "İ̧ yerinizde kullanılan cihazlar tasarruf özelliğine sahip midir?" sorusuna Şekil 3 'de görüldüğü üzere $\% 83$ "evet" yanıtı ile iş yerinde kullanılan cihazların tasarruf özelliğine sahip olduğunu belirtmiş̧lerdir. Hayır yanıtının alınmadı̆̆ı bu soruyu yöneticilerin \%17'si "bilmiyorum" şeklinde yanıtlamışlardır.

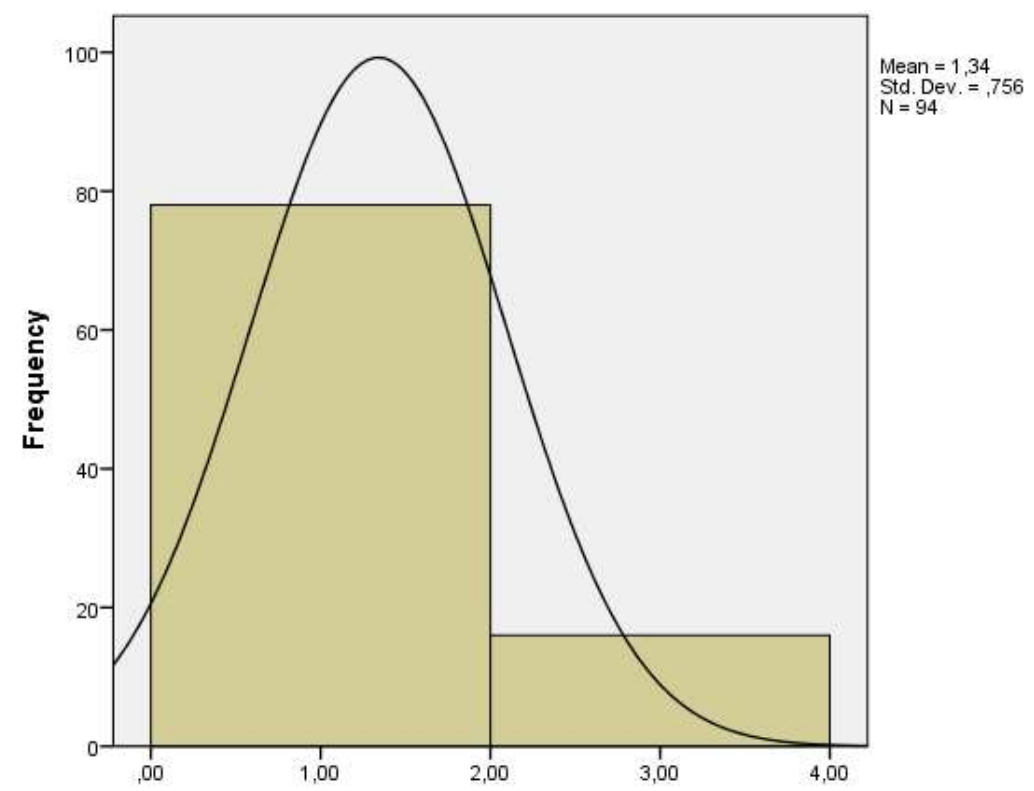

Şekil 3. İş yerinizde kullanılan cihazlar tasarruf özelliğine sahip midir? sorusunun bar grafiği

Kurumlarda yapılan anket çalışmasında "Bina dışı aydınlatmada herhangi bir tasarruf önlemi kullanilıyor mu?" sorusuna 94 yöneticinin 44'ü bu soruya "evet", 25'i "hayır", diğer 25 yönetici ise"bilmiyorum" yanıtını vermiştir. Yaklaşık \%47 evet cevabı ile iş yerinde bina dışı aydınlatmada tasarruf önlemi alındığı Şekil 4'de görülmektedir.

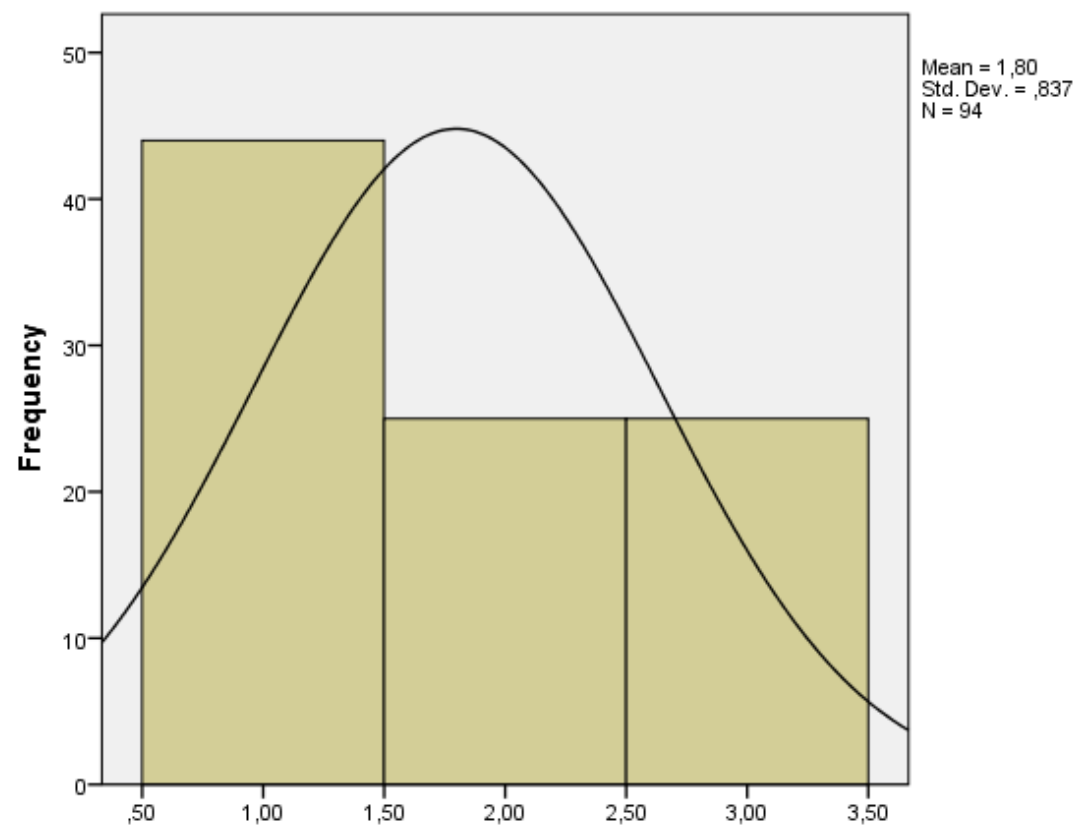

Şekil 4. Bina dışı aydınlatmada herhangi bir tasarruf önlemi kullanılıyor mu? sorusunun bar grafiği

Şekil 5'te görüldüğüü üzere, kurumlarda yapılan anket çalışmasında 94 yöneticinin 53’ü “Büyük ekranlı bilgisayarlar daha çok enerji tükettiği için, kurumunuzda bu konuda belirli bir standart uygulanıyor mu?" sorusuna? 52 yönetici "evet", 40 yönetici "hayır" ve 2 yönetici "bilmiyorum" yanıtını vermişlerdir. Bilgisayarlarda tasarruf önleminin alındığı, $\% 55$ evet yanıtı ile anlaşılmaktadır. Roberts ve 
Bacon'ın 1997 yılında yaptıkları çalışma [17] ile Pinto ve arkadaşlarının 2014 yılında yaptıkları çalışmalarda [18] enerji tasarrufu, doğal kaynakların sınırlı olduğu, fosil yakıt tüketiminin doğaya zarar verdiği dikkate alınarak temel ihtiyacı karşılayacak kaynak tüketiminden fazlasının yapılmaması gerektiği şeklinde tanımlanmıştır. Özellikle 2050 yılında dünya ekonomisinin bugünden 4 kat daha büyük olacağı ve günümüzden $\% 80$ daha fazla enerji ve doğal kaynağa ihtiyaç duyulacağ düşünüldügünde, enerji tasarrufunun ne denli önemli bir sorumlu tüketim davranış1 olduğu ortaya çıkmaktadır [19]. Bu bağlamda, yöneticilerin tasarrufla ilgili sorulara verdikleri olumlu yanıtlar su ve enerjinin sürdürülebilir kullanımı konusundaki duyarlılıklarını göstermektedir.

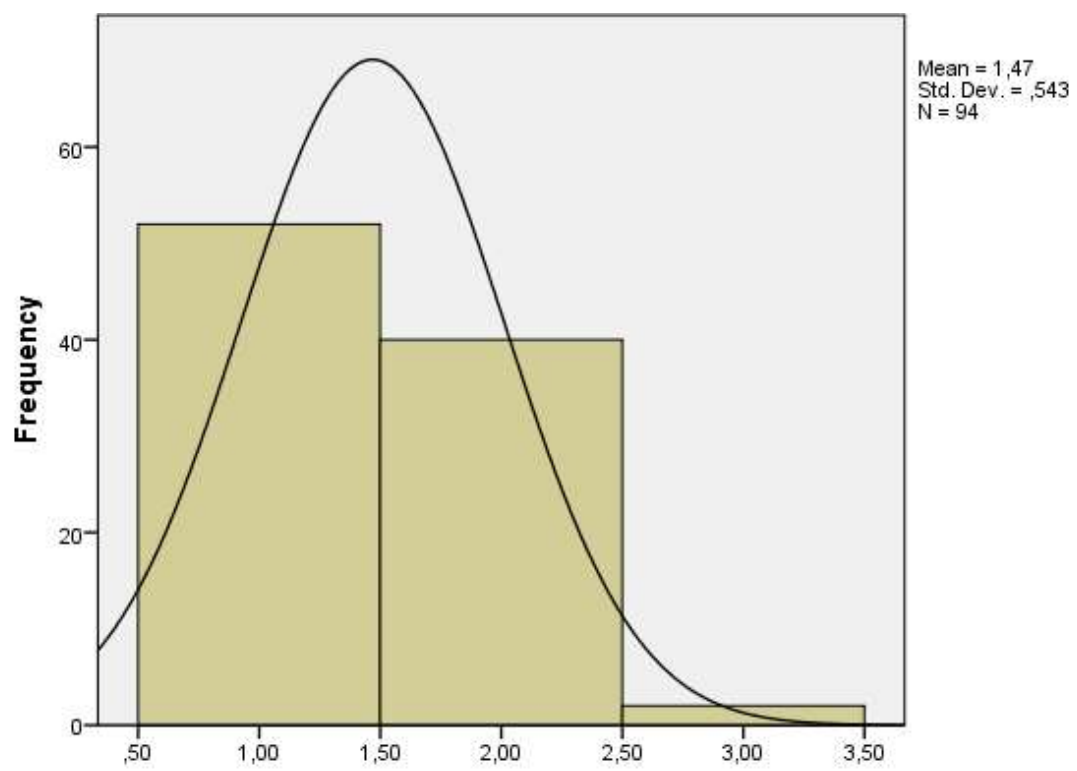

Şekil 5. Büyük ekranlı bilgisayarlar daha çok enerji tükettiği için, kurumunuzda bu konuda belirli bir standart uygulanıyor mu? sorusunun bar grafiği

"Su dağıtım ve iletim tesisatında TSE damgası olmayan malzeme kullanıllyor mu?" sorusuna 94 yöneticinin 50'si "evet", 27'si "hayır" ve kalan 17 yönetici ise "bilmiyorum" yanıtını vermişlerdir. "Evet" yanıtının \%53 olduğu bu soruda kurum binalarındaki su tesisatında TSE damgası olmayan malzeme kullanıldığı anlaşılmaktadır (Şekil 6). Bu durum yurtdışı menşeli düşük maliyetli malzemelerin tercih edildiğini göstermektedir.

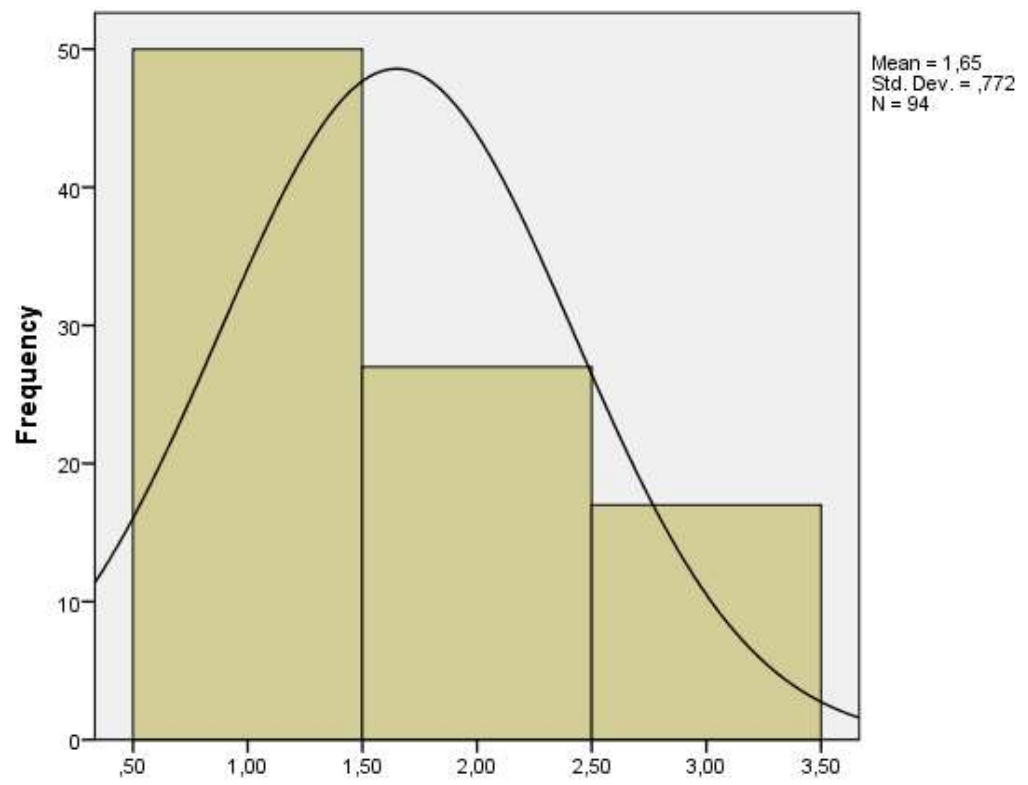

Şekil 6. Su dağıtım ve iletim tesisatında TSE damgası olmayan malzeme kullanılıyor mu?” sorusunun bar grafiği 


\section{Sonuçlar}

Önemli bir tarihi geçmişe sahip olan Bursa, Türkiye'nin 4. büyük kentidir. Gelişen sanayisi ve günümüzde yaklaşı 3 milyonluk nüfusuyla en fazla göç alan illerden birisidir. Bu nüfusun ihtiyacı olan içme ve kullanma suyunu Bursa'daki mevcut su kaynaklarının karşılayacak kapasitede olduğu görülmektedir. $\mathrm{Bu}$ amaçla, ilgili merci tarafından su temini konusunda yapılan çalışmalar (yeni su kaynaklarının belirlenmesi, baraj vb. su yapılarının projelendirilmesi, atıksuların geri kazanımı ve tekrar kullanımı amaçlı çalışmaların planlanması, suyun sürdürülebilir kullanımına yönelik tasarruf tedbirlerinin alınması gibi) devam ettirilmektedir. Diğer taraftan, ilde elektriğin tasarruflu kullanımı konusunda da çalışmalar sürdürülmektedir. Bu bağlamda, Bursa halkını elektrik tasarrufu konusunda bilgilendirme ve bilinçlendirme şeklinde yürütülen çalışmalarda, tasarruflu ve uzun ömürlü ampullerin tercih edilmesi, yüksek enerji sınıfında olan elektrikli aletlerin satın alınması, cihazların kullanılmadığı sürelerde bekleme konumunda bırakılmaması, 1sı kayıp ve kaçaklarının önlenmesine yönelik tedbirlerin alınması gibi yönlendirmelere yer verilmektedir.

Bu çalışma kapsamında, Bursa ili merkez ilçelerindeki kamu kurumlarının su ve elektrik tasarrufu konularındaki yaklaşımlarını belirlemek için, kurumlarda görev yapan 94 yöneticiye bir anket çalışması uygulanmıştır. Anket çalışmasında elde edilen veriler, SPSS programı kullanılarak istatistiksel olarak değerlendirilmiştir.

Değerlendirilmeler sonucunda;

- Yöneticilerin tasarruf konusunda çalşanlarına yönelik düzenli olarak bilgilendirme amaçlı etkinlikler düzenledikleri,

- Tasarrufu temin edecek şekilde görev yaptıkları kurum binalarının içinde ve dışında gerekli olan tüm bakım, onarım, yenileme çalışmalarını yürüttükleri,

- Kurum içinde kullanılan çeşitli cihazların yüksek enerji sınıfında olanların tercih edildiği ve periyodik bakımlarının düzenli olarak yaptırıldığı belirlenmiştir.

Sonuç olarak Bursa ili merkez ilçeleri kamu kurumlarının yöneticilerinin su ve elektrik tasarrufu konusunda duyarlı oldukları, kurum çalışanlarını teşvik ettikleri anlaşılmaktadır. Bu olumlu sonuç, ülkemizdeki mevcut kaynakların sürdürülebilir kullanımı konusunda önemli bir gelişme olup, bu çalışmanın gelecekte yapılacak daha kapsamlı bilimsel araştırmalara önderlik edeceği düşünülmektedir.

\section{Teşekkür}

$\mathrm{Bu}$ çalışmanın gerçekleştirilmesindeki katkılarından dolayı, Bursa Uludağ Üniversitesi Çevre Mühendisliği Bölümü öğrencilerine ve Bursa ili kamu kurum yöneticilerine çok teşekkür ederiz.

\section{Yazarların Katkısı}

Makalede yazarların katkısı eşit orandadır.

\section{Çıkar Çatışması Beyanı}

Yazarlar arasında herhangi bir çıkar çatışması bulunmamaktadır.

\section{Etik Kurallar}

Yapılan çalışmada, araştırma ve yayın etiğine uyulmuştur.

\section{Kaynaklar}

[1] Mengü G.P., Akkuzu E. 2008. Küresel Su Krizi ve Su Hasadı Teknikleri. Adnan Menderes Üniversitesi Ziraat Fakültesi Dergisi, 5 (2): 75-85.

[2] Burak M., Pehlivan E., Baran A., Çelik D., Nacar E., Çakmak E. 2017. Factors Influencing the Water Consumption Behaviors of the Medical Students at Inonu University. Medicine Science, 6 (2): 314-318. 
[3] Dünyada ve Türkiye'de Su Tüketimi, 2019. http://docplayer.biz.tr/259417-Dunya-da-ve-turkiyede-sutuketimi.html (Erişim tarihi: 27.03.2019).

[4] Türkiye su kıtllğı çekecek ülkeler arasında, 2015. http://www.hurriyet.com.tr/turkiye-su-kitligicekecek-ulkeler-arasinde-29933101 (Erişim tarihi: 27.03.2019)

[5] Kaya K., Şenel M.C., Koç E. 2018. Dünyada ve Türkiye'de Yenilenebilir Enerji Kaynaklarının Değerlendirilmesi. Technological Applied Sciences (NWSATAS), 2A0152, 13 (3): 219-234.

[6] Elektrik, 2019. http://www.enerji.gov.tr/tr-TR/Sayfalar/Elektrik (Erişim tarihi: 27.03.2019).

[7] Teksoy A., Erol Nalbur B., Akal Solmaz S.K. 2017. Assessment of Water and Wastewater Potential of Bursa City. Bursa Uludag University Journal of the Faculty of Engineering, 22 (1): 115-123.

[8] Bursa tanıtımı ve şehir rehberi, 2019. http://www.neyiilemeshur.com/bursa/bursa-tanitimi-vesehir-rehberi-3284.html (Erişim tarihi: 27.03.2019).

[9] Yalılı M., Akal Solmaz S.K., Kestioğlu K. 2006. Bursa Su Kaynakları Potansiyeli ve Kullanıcı Faktörü. Bursa Uludağ Üniversitesi Mühendislik Fakültesi Dergisi, 11 (2): 1-13.

[10] Doğru E. 2000. Bursa Şehri'nin Kuruluşundan İtibaren Yapılmış Olan Su Tesisleri. Lisans Bitirme Tezi, Bursa Uludağ Üniversitesi, Çevre Mühendisliği Bölümü, 120s, Bursa.

[11] Akal Solmaz S.K., Yalı1ı M. 2002. Bursa'nın İçme Suyu Meselesi ve Bazı Çözüm Önerileri. Ekoloji Çevre Dergisi, 11 (42): 36-39.

[12] Yalılı Kılıç M., Akal Solmaz S.K., Üstün G.E., Kestioğlu K. 2008. Su Temini Yönünden Bursa İli Su Kaynaklarının Bugünü ve Geleceği. Blacksea International Environmental Symposium BIES'08, 25-29 Ağustos, Giresun, 1-9.

[13] Yalılı Kılıç M., Akal Solmaz S.K., Çiner F. 2013. Kentsel Su Yönetiminde Su Kullanıcısının Önemi. 3. Uluslararası Bursa Su Kongresi, 22-24 Mart, Bursa, 598-605.

[14] Yalılı Kılıç M., Üstün G.E., Akal Solmaz S.K. 2016. Bursa İli Su Kaynaklarının Mevcut Durumunun Değerlendirilmesi. Çevre Mühendisleri Odası Çevre Bilim ve Teknolojisi Teknik Dergi, 1 (2): 12-26.

[15] Anonim, 2003. SPSS InstituteInc. SPSS Base 12.0User's Guide, 703p.

[16] Firidin E. 2015. Su Sorununun, Su Hakkı ve Su Etiği Çerçevesinde Değerlendirilmesi. Aksaray Üniversitesi İktisadi ve İdari Bilimler Fakültesi Dergisi, 7 (2): 43-55.

[17] Roberts J.A., Bacon R. 1997. Exploring the Subtle Relationships Between Environmental Concernand the Ecologically Conscious Consumer Behavior. Journal of Business Research, 40 (1): 79-89.

[18] Pinto D.C., Herter M.M., Rossi P., Borges A. 2014. Going Green for Self or for Others? Genderand Identity Salience Effects on Sustainable Consumption. International Journal of Consumer Studies, 38 (5): 540-549.

[19] Dursun İ., Belit M. 2017. Bir Sosyal Pazarlama Hedefi Olarak Enerji Tasarrufu ve Ölçümü. Ömer Halisdemir Üniversitesi İktisadi ve İdari Bilimler Fakültesi Dergisi, 10 (3): 130-153. 